\title{
Competitive priorities of manufacturing firms in the Caribbean
}

\author{
Suzana N. Russell ${ }^{1} \&$ Harvey H. Millar ${ }^{2}$ \\ ${ }^{1}$ Centre for Production Systems, University of Trinidad and Tobago, Trinidad W.I. \\ ${ }^{2}$ Sobey School of Business, Saint Mary's University, Halifax, Nova Scotia, Canada
}

\begin{abstract}
This paper seeks to examine the competitive priorities emphasized by manufacturing firms in the Caribbean. We study five manufacturing competitive priorities - quality, flexibility, cost, delivery and innovation. Survey data from 60 manufacturing firms in 4 Caribbean countries show that cost and quality are most strongly emphasized while innovation is the least emphasized. The findings from our study also provide support for the cumulative capabilities theory and show that Caribbean manufacturers are simultaneously emphasizing all five priorities and do not appear to be trading off one priority for another. In light of these findings, the implications for manufacturing managers and policymakers in the Caribbean and other developing economies are discussed.
\end{abstract}

Keywords: Caribbean; Competitive priority; Developing countries; Manufacturing strategy; Operations management

\section{Introduction}

The continued spectre of globalization certainly challenges Caribbean manufacturers to be competitive locally and internationally. As Bernal (2000) points out, in this new globalization it is not possible to insulate production or demand from global competition and changes. Small developing countries which are vulnerable to external events and have limited adjustment capacity are particularly exposed to the effects of globalization (Bernal, 2000). Over the years Caribbean manufacturers have had a tough time battling it out with global competitors and the relatively small size of the region as a market has done little to dissuade global competitors such as China, India and the United States. According to Takala et al. (2003), it is this pressure from globalization, coupled with rapid changes in technologies, which have increased the interest in competitive priorities among manufacturers.

Identifying manufacturers' competitive priorities has long been considered a key element in manufacturing strategy research (Ward et al., 1998). Over the years several empirical studies have sought to examine the competitive priorities and manufacturing strategies of different countries, regions and sectors. For example, Burgess et al. (1998) and more recently Bülbül (2011) examined the competitive priorities of firms in Turkey; Zhao et al. (2002) studied enterprises in mainland China; Dangayach and Deshmukh (2003) looked at Indian manufacturing firms; Phusavat and Kanchana (2007) studied the competitive priorities of manufacturing firms in Thailand while Rosli (2012) looked at Malaysian SMEs; Amoako-Gyampah and Acquaah (2008) studied manufacturing firms in Ghana and Krüger (2012) looked at South African businesses. Despite the extensive studies on several countries, Naqshbandi and Idris (2012) note that the competitive priorities in the developing world have hardly been studied. In discussing this observation in reference to Africa, AmoakoGyampah and Boye (2001) pondered whether the apparent lack of interest might be due to the perception that African countries do not represent a viable source of information and analysis with regards to manufacturing. This is even more apparent for Caribbean countries as only a few studies, such as Lawrence (2007), have looked at the competitive priorities of any Caribbean country. This paper is a modest attempt to fill this void by adding to the manufacturing strategy literature on developing economies, and as pointed out by Amoako-Gyampah and Boye (2001), broaden the area for data collection beyond traditional sites. It is relevant because although the Caribbean may be relatively small in terms of population its economic environment is similar to other developing regions such as Latin America and parts of Asia and Africa, and as such may provide useful insights. Moreover, with trade liberalization, the once vibrant manufacturing sector in the Caribbean bore the brunt of import competition as these countries' industries, which were developed on the basis of import-substituting industrialization, were unable to compete with cheaper imported manufactured products (ECLAC, 2002). This resulted in the rapid decline of the contribution of manufacturing to GDP for many countries. For example, Saint Lucia's manufacturing contribution to GDP declined from 8.4 in 1980 to 5.1 in 2000, and Barbados also showed a decline from 12.5 to 6.2 over the same period (Downes, 2004).

Caribbean manufacturers are facing intense competition from international markets and therefore it is imperative for companies to emphasize strategies that will enable them to be competitive. However, as noted, there is a dearth of research in this area. The main aim of this study is to examine the competitive strategies emphasized by Caribbean manufacturers. This paper attempts to answer the following research question: What 
competitive strategies are most emphasized by Caribbean manufacturers? In order to answer this question the following objectives are set:

- To investigate the relative importance of different competitive priorities among Caribbean manufacturing firms

- To determine whether there are trade-offs among the competitive priorities emphasized, that is, whether Caribbean manufacturers focus on one priority or simultaneously emphasize several priorities

- To examine whether contingency factors such as firm age and size impact the choice of competitive priorities

- To explore the relationships between the competitive priorities emphasized and manufacturing decisions/practices employed

This study is based on a survey of the competitive strategies of manufacturing firms in 4 countries in the Southern Caribbean. The primary contribution of this paper is to the extant literature on manufacturing strategy by providing empirical evidence from a developing economy perspective. Since the majority of firms operating in the Caribbean are considered small to medium sized (Chida, 2000), a secondary contribution of this paper is to complement existing manufacturing strategy literature on SMEs.

The remainder of the paper is organized as follows. The next section provides a brief review of manufacturing competitive priorities and defines the competitive priorities used in this study. Next we discuss the research methods and introduce the sources of data in section III. The results of the study are then presented and analyzed in section IV, followed by a discussion of the implications for research and practice in section $\mathrm{V}$. We also reflect on the research and discuss avenues for future research in this section.

\section{Manufacturing competitive priorities}

The strategic notion of operations as a competitive weapon dates back to the 1960s (Sum et al., 2004). Skinner (1969) is often credited with founding the extensive manufacturing strategy literature (Burgess et al., 1998). Skinner (1969) observed that a company's manufacturing function could have a role to play in a firm's competitive abilities. Skinner (1974) went on to describe some common competitive measures for manufacturing strategy such as short delivery cycles, dependable delivery, superior product quality and reliability, flexibility in volume changes, the ability to produce new products quickly and low cost. In 1984, Hayes and Wheelwright introduced the term 'competitive priorities', which they defined as strategic preferences or the dimensions along which a company chooses to compete in the targeted market. Leong et al. (1990) term competitive priorities as a consistent set of goals for manufacturing to gain competitive advantage. Several labels or terminologies are often used in the literature including: competitive devices or methods, strategic choice attributes, competitive strategy variables, manufacturing competitive priorities, performance objectives and customer requirements (Krüger, 1997). Over the years numerous articles have been published using a multiplicity of competitive priorities. In fact, White (1996) surveyed a wide variety of literature and found several hundred measures. However, Vickery et al. (1997) point out that the literature reduces this exhaustive list to about 4 or 5 core dimensions. Therefore, despite the numerous priorities identified in the manufacturing strategy literature, the widely accepted competitive priorities are cost, delivery, quality and flexibility (Kathuria, 2000). Leong et al. (1990) introduced a fifth competitive priority called innovativeness.

For this research, we use the 5 agreed upon manufacturing competitive priorities, which we discuss below. Given the multi-dimensional nature of these priorities, multiple items or dimensions are typically used to define them and capture a manufacturer's emphasis on each priority.

Cost: Cost is defined as production and distribution at low cost (Dangayach and Deshmukh, 2003). Competing on cost focuses on the ability to effectively manage production cost, including its related aspects such as overhead, inventory and value-added (Phusavat and Kanchana, 2007). Zhao et al. (2002) further describe this as the ability to reduce product cost by reducing overheads, labour, raw materials costs and production cycle time. In this study, we use aspects of cost to include reducing production costs, overhead, material and inventory costs.

Quality: One way of defining quality is the extent to which the manufacturing enterprise is capable of offering product quality that would fulfill customer's expectation (Koufteros et al., 2002). Garvin (1987) suggests 8 dimensions of quality, namely: performance, features, reliability, conformance, durability, serviceability, aesthetics and perceived quality. In their study, Phusavat and Kanachan (2007) use items such as low defect rate, product performance, reliability, certification and environmental concerns to represent quality. Zhao et al. (2002) use items including reliability, durability, performance, conformance, ability to reduce environmental damages and the ability to improve working conditions and safety. We use 8 dimensions of quality including performance, reliability, durability and design quality.

Flexibility: Flexibility is the ability to react to changes in production, changes in product mix, modifications in design, fluctuations in materials, and changes in sequence (Dangayach and Deshmukh, 2003). Measures of 
flexibility used by Ward and Duray (2000) include lead time reduction, setup time reduction and the ability to change priorities of jobs on the shop floor. Measures of flexibility used in our study include reducing setup and change-over times, the ability to handle changes in customer delivery schedules, ability to rapidly change product mix and production volumes.

Delivery: Delivery usually refers to both speed and dependability. Spring and Boaden (1997) define delivery dependability as meeting delivery schedules and delivery speed as reacting quickly to customer orders. We use dimensions that are consistent with these definitions such as increasing delivery speed and improving on-time delivery. We also include after-sales service as a measure of delivery, similar to Robb and Xie (2003).

Innovation: Innovation is defined as the introduction of new products and processes (Dangayach and Deshmukh, 2003), but it also speaks to a firm's ability to make improvements to existing products and processes. In addition, it refers to the ability to implement new technologies and the ability to create new markets (Zhao et al., 2002). Measures of innovation used in our study include the adoption of new technology, reduction of product development time and introduction of new products.

\subsection{Trade-offs}

According to Boyer and Lewis (2002) a heated debate continues over the need for trade-offs in operations strategy. The notion of trade-offs in the manufacturing strategy literature suggests that a company cannot excel simultaneously on all competitive priorities (Davis et al., 2005, p.40). As Dilworth (1993) puts it 'a company usually cannot be all things to all customers'. Consequently management has to decide which priorities are critical to a firm's success and then concentrate or focus the resources of the firm on these particular characteristics (Davis et al., 2005). In fact, it was Skinner (1969) who advocated the trade-off model by positing that companies must make choices regarding which competitive priorities should receive the greatest investment of time and resources. However, there is also the other perspective that manufacturers do not have to make trade-offs and are able to simultaneously emphasize multiple competitive priorities (Rosenzweig and Roth, 2004). This cumulative capabilities theory suggests that trade-offs are not necessary and a company can pursue multiple dimensions simultaneously (Nakane, 1986; Noble, 1995). Ferdows and De Meyer (1990) propose a 'sand cone model' which suggests that plants can avoid tradeoffs by following a pre-specified order for developing manufacturing capabilities: first selecting high quality, then dependable delivery, followed by low cost and flexibility. Several empirical studies have sought to test the trade-off and cumulative capabilities theories. Flynn and Flynn (2004) used data from 167 manufacturing plants from 5 countries which provided support for the cumulative capabilities theory. Amoako-Gyampah and Meredith (2007) studied 126 manufacturing firms in Ghana and found that the evidence also supported the cumulative capabilities theory. They found no trade-offs between the capabilities of quality, cost, delivery and flexibility. Although not the main focus of this study, we sought to investigate whether Caribbean manufacturing firms are emphasizing a single priority or simultaneously emphasizing several priorities.

\subsection{Sample and data collection}

\section{Research methods}

Our study examines the competitive priorities of manufacturing firms in 4 Caribbean countries: Trinidad and Tobago, Guyana, St Lucia and Barbados. These countries account for the majority of manufacturing in the Caribbean region, along with Jamaica, which did not participate in our study. We used two approaches to obtain data for this research. First, the questionnaire and a cover letter explaining the purpose of the study were sent to the respective manufacturing associations in each of the 4 countries. The associations then sent solicitation letters to their members inviting them to participate in the online survey that was posted on the associations' websites. Several follow-up reminders were sent to the associations, who in turn reminded their members to complete the survey. After 2 months, only 8 companies from the 4 countries had completed the questionnaire. In order to increase the dataset we decided on a second approach. In conjunction with the manufacturing associations, we organized a seminar on manufacturing strategy and the associations invited their members to attend. The companies were informed beforehand that they would be invited to complete the questionnaire at the start of the seminar. Over a 2-week period, we delivered 4 sessions on manufacturing strategy in the 4 countries. Fifty-two (52) companies participated in this round.

\subsection{Variables and measures}

Consistent with several empirical studies we used composite measures to determine the emphasis on 5 competitive priorities: quality, flexibility, cost, delivery and innovation. A total of 30 items were used as measures for these constructs: quality ( 8 measures), flexibility ( 8 measures), cost ( 5 measures), delivery (5 measures) and innovation (4 measures). It should be noted that the number of priorities and corresponding measures vary in the literature. For example, Phusavat and Kanchana (2007) and Phusavat and Kanchana (2008) in similar studies used 6 priorities and 31 measures and Zhao et al. (2002) used 6 priorities and 28 measures. In 
an attempt to 'customize' the dimensions to more closely reflect the Caribbean environment, in addition to the measures from the extant literature, we asked for suggestions from 5 manufacturing companies, who are members of the Trinidad and Tobago Manufacturers' Association (TTMA). Based on their feedback our final questionnaire reflected 2 additional measures - one for cost (running the equipment at peak efficiency) and the other for delivery (improving pre-sales service and technical support).

According to Koufteros et al. (2002) researchers typically conceptualize competitive priorities by asking respondents to attribute a level of importance to given dimensions. In our study respondents were asked to indicate their level of emphasis on the 5 competitive priorities over the last 2-3 years. They were asked to respond using a 5-point Likert scale with ' 1 ' representing least emphasized and ' 5 ' representing strongly emphasized. In addition, respondents were asked to indicate whether they have implemented specific manufacturing practices in support of the respective competitive priorities.

\subsection{Reliability assessment}

For composite variables, a common measure used to assess reliability is the internal consistency of items included in a construct, which is measured using Cronbach's alpha. We assess the reliability of our constructs by evaluating the Cronbach's alpha for each of our 5 competitive priorities. Cronbach's alpha values are $0.87,0.90,0.95,0.92$ and 0.92 for quality, flexibility, cost, delivery and innovation, respectively. These values are all greater than 0.7 which is generally acceptable for a construct (Nunnally, 1978), and therefore suggests acceptable internal consistency.

\subsection{Construct validity}

A factor analysis was conducted to examine convergent and discriminant validity. Table 1 shows that all items load higher on their respective factors than on other constructs. The cumulative variance explained by the 5 factors is $75.16 \%$. For simplicity, only loadings above 0.4 are shown.

Table 1: Factor analysis

\begin{tabular}{|c|c|c|c|c|c|}
\hline \multirow{2}{*}{ Measures } & \multicolumn{5}{|l|}{ Factors } \\
\hline & Flexibility & Innovation & Quality & Cost & Delivery \\
\hline Improving product quality & & & .756 & & \\
\hline Improving product performance & & & .759 & & \\
\hline Improving product reliability & & & .838 & & \\
\hline Improving supplier quality & & & .71 & & \\
\hline Improving product durability & & & .672 & & \\
\hline Improving design quality & & & .599 & & \\
\hline Meeting customer needs & & & .551 & & \\
\hline The prompt handling of customer complaints & & & .544 & & \\
\hline Reducing setup and change-over times & .732 & & & & \\
\hline Reducing procurement lead times & .729 & & & & \\
\hline The ability to rapidly change product mix & 685 & & & & \\
\hline The ability to rapidly change production volumes & .834 & & & & \\
\hline $\begin{array}{l}\text { The ability to manufacture a wide variety of } \\
\text { products }\end{array}$ & .744 & & & & \\
\hline The ability to handle custom orders & .737 & & & & \\
\hline $\begin{array}{l}\text { The ability to modify product features of pre- } \\
\text { existing products }\end{array}$ & .528 & & & & \\
\hline Handling changes in customer delivery schedules & .696 & & & & \\
\hline Improving labour productivity & & & & .793 & \\
\hline Reducing overhead costs & & & & .762 & \\
\hline Reducing inventory costs & & & & .700 & \\
\hline Reducing material costs & & & & .746 & \\
\hline Running equipment at peak efficiency & & & & .764 & \\
\hline Improving on-time delivery & & & & & .878 \\
\hline Increasing delivery speed & & & & & .913 \\
\hline Reducing manufacturing lead times & & & & & .861 \\
\hline Improving pre-sales service and technical support & & & & & .796 \\
\hline Improving after-sales service & & & & & .676 \\
\hline Timely introduction of new products to the market & & .808 & & & \\
\hline Reducing new product development time & & .725 & & & \\
\hline Adopting new manufacturing technology timely & & .651 & & & \\
\hline Increasing new product development & & .777 & & & \\
\hline
\end{tabular}

\section{Results}

\subsection{Demographic data}

This study involved a survey of 60 manufacturing firms in 4 Caribbean countries: Trinidad and Tobago (38.3\% of respondents); Barbados (18.3\%); Guyana (28.3\%) and St. Lucia (15\%). Table 2 shows the demographic data of the firms in our study. A breakdown of the firms according to sectors and other descriptive 
are presented in this table. Almost $90 \%$ of the respondents occupied senior positions in their organizations such as CEO, director of manufacturing, managing director and operations manager. We can therefore assume a certain level of credibility with the responses given as these persons would have adequate knowledge of the strategies of their firms. The majority of the firms $(80 \%)$ have been operating for more than 10 years and can be considered mature organizations. Only $12 \%$ of the firms were in operation for less than 5 years and may be classified as new or start-ups. Ninety-five per cent (95\%) of the companies in our sample employ less than 250 persons and are therefore considered SMEs in accordance with the definition by the European Commission (CEC, 1996). Eighty-three per cent (83\%) of the respondents indicate that less than $50 \%$ of their annual sales come from exports, which suggests that these manufacturers cater primarily to a domestic market.

Table 2: Demographic data for participating manufacturing firms

\begin{tabular}{|c|c|c|}
\hline Descriptive (sample size) & Frequency & Per cent \\
\hline \multicolumn{3}{|l|}{ Country data $(\mathrm{n}=60)$} \\
\hline Barbados & 11 & 18.3 \\
\hline Guyana & 17 & 28.3 \\
\hline Trinidad & 23 & 38.3 \\
\hline St. Lucia & 9 & 15.0 \\
\hline \multicolumn{3}{|l|}{ Age of firm $(n=60)$} \\
\hline$<5$ yrs & 7 & 11.7 \\
\hline $5-<10 y r s$ & 5 & 8.3 \\
\hline $10-<15 y r s$ & 10 & 16.7 \\
\hline$>15 y r s$ & 38 & 63.3 \\
\hline \multicolumn{3}{|l|}{ Number of employees $(n=60)$} \\
\hline$<50$ & 33 & 55.0 \\
\hline $50-<100$ & 6 & 10.0 \\
\hline $100-<250$ & 18 & 30.0 \\
\hline $250-<500$ & 1 & 1.7 \\
\hline$>500$ & 2 & 3.3 \\
\hline \multicolumn{3}{|l|}{ Job title $(n=60)$} \\
\hline Plant manager & 4 & 6.7 \\
\hline Production/Operations manager & 9 & 15.0 \\
\hline General manager & 26 & 43.3 \\
\hline Other & 21 & 35.0 \\
\hline \multicolumn{3}{|l|}{ Industry sector $(\mathrm{n}=60)$} \\
\hline Food, beverages and tobacco & 13 & 21.7 \\
\hline Paper products, printing, packaging & 9 & 15.0 \\
\hline Chemicals and chemical products & 3 & 5.0 \\
\hline Textiles, apparel and leather & 3 & 5.0 \\
\hline Wood, wooden products and fittings & 4 & 6.7 \\
\hline Rubber and plastic products & 4 & 6.7 \\
\hline Stone, clay, glass and concrete products & 2 & 3.3 \\
\hline Fabricated metal products & 9 & 15.0 \\
\hline Machinery, equipment and instruments & 5 & 8.3 \\
\hline Other manufacturing & 8 & 13.3 \\
\hline \multicolumn{3}{|l|}{ Annual sales $(\mathrm{n}=60)$} \\
\hline Under US\$500,000 & 13 & 21.7 \\
\hline US\$500,000- $<$ US\$5mil & 26 & 43.3 \\
\hline US\$5 mil - < US\$25mil & 16 & 26.7 \\
\hline US\$25mil - < US\$50mil & 3 & 5.0 \\
\hline$>\mathrm{US} \$ 50 \mathrm{mil}$ & 2 & 3.3 \\
\hline \multicolumn{3}{|c|}{ Level of export as percentage of total sales $(n=59)$} \\
\hline $1 \%-<25 \%$ & 12 & 20.3 \\
\hline $25 \%-<50 \%$ & 20 & 33.9 \\
\hline $50 \%-<75 \%$ & 17 & 28.8 \\
\hline \multirow[t]{2}{*}{$>75 \%$} & 7 & 11.9 \\
\hline & 3 & 5.1 \\
\hline
\end{tabular}

\subsection{Emphasis on competitive priorities}

To determine the level of emphasis placed on the competitive priorities, we compute the mean score for each. The competitive priorities are then ranked based on these scores. Table 3 shows the means, standard deviations and ranks for all 5 competitive priorities. The results show that, on average, all 5 priorities are only moderately emphasized by Caribbean manufacturers; none has an average score exceeding 4.0. 
Table 3: Means and ranks of all competitive priorities

\begin{tabular}{llll}
\hline & Mean & Std. deviation & Rank \\
\hline Cost & 3.69 & 1.265 & 1 \\
Quality & 3.54 & 1.054 & 2 \\
Delivery & 3.53 & 1.233 & 3 \\
Flexibility & 3.09 & 1.195 & 4 \\
Innovation & 2.79 & 1.376 & 5 \\
\hline
\end{tabular}

The most emphasized competitive priority is cost, which shows that Caribbean manufacturers still view cost as the most important factor in helping them to win customer orders and gain a competitive edge. In looking at the measures of cost used in the study respondents rated 'improving labour productivity' (mean $=$ 3.95) as the most strongly emphasized aspect of cost reduction. This is largely driven by the fact that many manufacturing facilities in the Caribbean are still highly labour intensive. Low labour productivity in the Caribbean, coupled with the small size and high labour costs make these industries unviable when competing with low labour costs giants like India and China (OTF Group, 2005). It is therefore important that workers are as productive as possible. The least emphasized aspect of cost is reducing material costs (mean $=3.58)$. This is probably because a large majority of the input materials used in local production is imported and Caribbean manufacturers believe they have few opportunities for any further cost reductions. It also appears that these companies do not think they can reduce overhead costs substantially as it was the second least emphasized aspect of cost. It appears that the possibility for additional cost reduction is low and therefore these manufacturers have shifted their efforts to productivity improvement.

Table 3 shows that quality and delivery have almost similar means, which reflects the fact that manufacturers realize they also need to focus on these priorities (as well as cost) to win orders. Of the 8 measures of quality studied, 'improving conformance quality' and 'meeting customer needs' (both with mean = 4.12) are ranked highest, followed by 'the prompt handling of customer complaints' (mean = 3.92). Caribbean manufacturers seem to understand that economic survival depends on meeting products specifications and addressing the needs of customers, including dealing with customers' complaints, in a timely manner. The most emphasized aspect of delivery is dependability or 'improving on-time delivery' (mean $=4.02$ ). This is consistent with the strong emphasis on meeting customers' needs (quality). These results seem to show that the firms in the study are clearly customer-focused, which is deemed vital based on the high level of custom-orders these manufacturers receive (respondents indicate that more than $75 \%$ of their goods are made-to-order).

Innovation is the least important of the 5 competitive priorities. The mean score of 2.79 is less than the mid-score of 3 , and shows that most companies either do not realize the importance of innovation in being competitive or are not experiencing pressures to innovate.

\subsection{The most and least emphasized competitive priority items}

The 5 most important and least important competitive priority items are shown in Table 4 . The least emphasized competitive items relate to flexibility and innovation. Of the 30 priority items used in the study, manufacturers place the least emphasis on reducing the time for new product development. In fact, 3 of the 4 items used to measure innovation fall within the category of the least important items, which shows that there is little focus on using innovation as a source of competitive advantage. Of the 5 most emphasized items, 3 are quality measures. The top 3 most important items, with a score above 4 out of a maximum of 5 , are all interrelated and customer-centric. Improving delivery dependability, meeting customers' needs, on-time delivery and a focus on conformance quality all relate to customer satisfaction.

Table 4: Means and rank order for the most important and least important priority items

\begin{tabular}{|c|c|}
\hline Most important items & Least important items \\
\hline $\begin{array}{lr}\text { Improving conformance quality (quality) } & 4.12(1) \\
\text { Meeting customers' needs (quality) } & 4.12(1) \\
\text { Improving on-time delivery (delivery) } & 4.02(2) \\
\text { Improving labour productivity (cost) } & 3.95(3) \\
\text { Handling customer's complaints promptly (quality) } \\
3.92 \text { (4) }\end{array}$ & 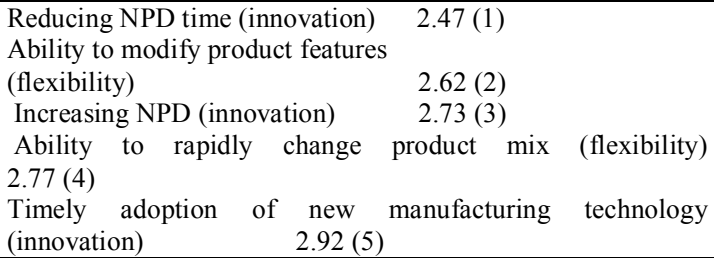 \\
\hline
\end{tabular}

\subsection{Contingency factors}

In order to provide further insight into the competitive strategies of Caribbean manufacturing firms one of the objectives of the study was to determine whether factors such as firm size and age affect the choice of priorities. The results are shown in Table 5. These results reveal no differences in the priorities emphasized based on firm size, which suggest that the size of the firms is not an influencing factor on competitive priorities emphasized. As it relates to the age of the firm, cost and innovation emerged as the only priorities having 
significant differences in means. A comparison of the means shows that mature firms are placing more emphasis on cost and innovation than young firms. In fact, the high emphasis placed on cost (mean $=4.15)$ suggests that mature firms view this as the most important competitive priority. For annual sales, we observe differences in the competitive priorities of flexibility, cost and innovation. Our results suggest that firms with higher sales seem to be more strongly emphasizing these 3 priorities when compared to firms with low sales. We also compare competitive priorities emphasized based on the profitability of the firms. Our results show no link between the profitability of the firms in our study and the competitive priorities emphasized.

Table 5: Contingency factors and competitive priorities emphasized

\begin{tabular}{|l|l|l|l|l|}
\hline $\begin{array}{l}\text { Grouping } \\
\text { variable }\end{array}$ & Group 1 & Group 2 & Group 3 & Results \\
\hline Firm size & $\begin{array}{l}\text { Small firms } \\
(<50 \text { employees })\end{array}$ & $\begin{array}{l}\text { Medium firms } \\
(50-<250 \text { employees })\end{array}$ & $\begin{array}{l}\text { Small firms } \\
(>250 \text { employees })\end{array}$ & No statistical difference \\
\hline Age & Young $(<10$ yrs $)$ & Mature $(>10$ yrs $)$ & - & $\begin{array}{l}\text { Cost } \\
\text { Innovation }(\mathrm{t}=2.366, \mathrm{p}=.02)\end{array}$ \\
\hline Annual sales & Low sales $(<\mathrm{US} \$ 5 \mathrm{M})$ & High sales ( $>$ US\$5M) & - & $\begin{array}{l}\text { Flexibility }(\mathrm{t}=2.280, \mathrm{p}=.026) \\
\text { Cost } \\
\text { Innovation }(\mathrm{t}=2.782, \mathrm{p}=.007)\end{array}$ \\
\hline Profitability & No profit in last $2-3$ yrs & Profit in last $2-3$ yrs & - & No statistical difference \\
\hline
\end{tabular}

\subsection{Trade-offs}

Similar to work by Noble (1995), trade-offs can be confirmed through significant positive relationships among the emphasis given to manufacturing capabilities. Table 6 shows the correlations among the 5 competitive priorities studied. All the correlation coefficients are positive and significant $(p<0.01)$, which according to Schoenherr et al. (2012), is indicative of the multiple reinforcement of capabilities on each other. These results suggest that the manufacturers in our study are emphasizing multiple competitive priorities in their organizations, with no evidence of tradeoffs.

Table 6: Intercorrelations among competitive priorities

\begin{tabular}{lllll}
\hline & Quality & Flexibility & Cost & Delivery \\
\hline Flexibility & $.631^{* *}$ & & & \\
Cost & $.628^{* *}$ & $.712^{* *}$ & & \\
Delivery & $.592^{* *}$ & $.841^{* *}$ & $.675^{* *}$ & \\
Innovation & $.518^{* *}$ & $.636^{* *}$ & $.475^{* *}$ & $.462^{* *}$ \\
\hline
\end{tabular}

** Correlation is significant at the 0.01 level (2-tailed)

\subsection{Relationship between priorities and practices}

A firm's manufacturing strategy should be reflected in its operations decisions or practices which should result in some desired manufacturing objectives. Table 7 shows the correlations between the competitive priorities and manufacturing practices implemented over the last 2-3 years.

Table 7: Competitive priorities and manufacturing practices

\begin{tabular}{|c|c|c|c|c|}
\hline \multirow[b]{2}{*}{ Competitive priority } & \multicolumn{4}{|c|}{$\begin{array}{l}\text { Manufacturing } \\
\text { practices }\end{array}$} \\
\hline & Cost & Flexibility & Quality & Delivery \\
\hline Quality & $.302^{* *}$ & $.437^{* *}$ & $.363^{* *}$ & $.409^{* *}$ \\
\hline Flexibility & $.688^{* *}$ & $.661^{* *}$ & $.682^{* *}$ & $.618^{* *}$ \\
\hline Cost & $.561^{* *}$ & $.578^{* *}$ & $.621^{* *}$ & $.468^{* *}$ \\
\hline Delivery & $.548^{* *}$ & $.659^{* *}$ & $.660^{* *}$ & $.593^{* *}$ \\
\hline
\end{tabular}

** Correlation is significant at the 0.01 level (2-tailed)

Our results show that all relationships are significant and positive. We note that the strongest relationships do not necessarily exist between a priority and its corresponding practice. Because there are no trade-offs among priorities and manufacturers are simultaneously emphasizing several priorities, it is possible that while the companies acknowledge principal focus on a single priority they are also implementing practices and making manufacturing decisions in support of all priorities.

\section{Discussion and Conclusion}

The main objective of this study was to examine the competitive priorities of Caribbean manufacturing firms. We note several interesting findings from our study. Our results reveal that of the 5 competitive priorities studied cost is most strongly emphasized. This is interesting as there is the view that the traditional mind set of competition based on lower cost is no longer effective in today's marketplace (Zhao et al., 2002). However, the 
strong emphasis on cost may be linked to the economic environment in the Caribbean. In the 1990s, trade liberalization, market opening and access stipulations by developed countries meant that the era of preferences once enjoyed by countries in the region, were fast coming to a close (ECLAC, 1999). Since then the region has seen an influx of imported goods from low cost producers from countries like India and China. Caribbean manufacturers have been unable to produce goods cheaper than the price of equivalent imports largely because of constraints in material and labour inputs as well as the high costs of utilities and transportation. As a result of these constraints manufacturers in the region are forced to look towards low-cost manufacturing. The manufacturers in our study are emphasizing improved labour productivity and operating efficiency as means of reducing cost, as opposed to sourcing low cost materials and reducing overhead costs. These manufacturers are mainly emphasizing internal factors that they can control (such as labour and equipment performance), rather than external factors such as material cost. In a region that has seen only modest growth in some countries and decline in many, local consumers are very price-sensitive and as such cost appears to an order winner for Caribbean manufacturers. This is in contrast to more developed economies where it is an order qualifier (Amoako-Gyampah and Acquaah, 2008).

Quality ranked closely behind cost as the second most strongly emphasized competitive priority. Our results show that 3 of the top 5 priority items relate to quality. It is encouraging that Caribbean manufacturers are emphasizing capabilities in quality as according to ECLAC (2007) it is a most important factor in competitiveness, particularly for small producers with low production volumes, as characterized by the majority of firms in our study. High quality products and a customer-centric focus have the potential to lead to brand loyalty. This is especially important in the Caribbean region where local consumers still perceive imported manufactured goods, particularly from Europe and USA, are of higher quality that locally produced goods. As such, firms that emphasize quality are more likely to build a reputation by changing this perception and therefore gain market share and sales growth (Amoako-Gyampah and Acquaah, 2008). Khanna and Palepu (2006) posit that if emerging-market companies improve the quality of their products, they are able to cater to local customers, if not better, than multinationals. Our findings seem to show that, like cost, while quality has become an order qualifier in many international markets, it still has potential as an order winner in Caribbean markets.

We confirm the 'traditional view' that firms in the Caribbean are still driven by cost, quality, flexibility and delivery as it appears that innovation is not yet a main focus for Caribbean manufacturers. Although the Ministry of Trade and Industry (2011) believes the future of Caribbean manufacturing should see firms seeking to achieve quantum levels of innovation in pursuit of competitiveness, our findings indicate that this is not presently happening. Reasons for the lack of emphasis on innovation may be attributed to the small size of many Caribbean firms and the fact that they are likely to be undercapitalized, making it difficult to invest in research and development. Moreover, similar to the observation of Amoako-Gyampah (2003) for Ghanaian firms, most of the firms in our study are not in industries that would be considered high technology-based and therefore innovation is not of great concern to these companies. Our findings differ from Thürer et al. (2013) on Brazil, which shows that manufacturers are now focusing on innovation rather than the traditional focus on cost.

Of the 30 priority items studied our findings reveal that Caribbean manufacturers are placing the least emphasis on reducing the time for new product development, developing new products and adopting new manufacturing technology. Caribbean countries are expected to lag behind developed, mature nations in the adoption of new and emerging technology. Dangayach and Deshmukh (2001) explain that SMEs are less oriented to advance their technological capabilities due to a lack of funds. Therefore, rather than focusing on innovation the firms in our study are attempting to win orders by primarily focusing on cost and quality. The other two of the least 5 emphasized priority items relate to flexibility - modifying product features and changing product mix. Amoako-Gyampah and Acquaah (2008) point out that a flexibility strategy is usually appropriate if a manufacturer is trying to shape the market in which it competes. For example, firms in several developing economies like South Korea, Taiwan, Singapore and Hong Kong, have managed to change their roles from contract manufacturing of standardized components to competitors of finished products (Sakhter and Pounder, 2008). This is not the case in the Caribbean where manufacturers are largely contract manufacturers and hence the low emphasis on achieving flexibility in relation to the other priority items.

We also show that cumulative capabilities exist within the Caribbean manufacturing environment. Manufacturers do not appear to be trading off one capability for another as all the competitive priorities are simultaneously emphasized. Our findings are consistent with Lawrence (2007) who examined the competitive priorities of 101 small businesses in Jamaica and found no trade-offs among competitive priorities. Our result is also similar to those by Amoako-Gyampah and Meredith (2007) in a study of firms in Ghana, a developing economy with similar economic environment to the Caribbean. Amoako-Gyampah and Meredith (2007) point out that these findings should be expected for the manufacturing environment in less developed economies, where firms are so far within their performance frontier that one should not expect trade-offs among competitive priorities as developing countries do not have the luxury of just focusing on one capability. 
We examined whether there was a link between factors such as firm age, size, sales and profitability and the choice of competitive priorities. We found differences for two of these contingency factors - the age of the firm and annual sales. As it relates to the age of the firm, mature firms are more strongly emphasizing cost and innovation. Older firms appear to have realized over time that in order to be competitive they need to focus their limited resources on cost reduction and greater labour productivity. With experience, these firms have also recognized the importance of product innovation and the timely introduction of new products to the market. Since the majority of the firms in our study cater to the domestic market, which is fairly small, companies that introduce new products or make incremental improvements to existing products are more likely to win orders. It is not entirely surprising then that our results show that firms with high annual sales place more emphasis on the competitive priorities of cost, flexibility and innovation when compared to firms with low sales.

\subsection{Managerial and policy implications}

The survival of manufacturing in the Caribbean will depend on the extent to which manufacturers in the region can remain competitive in spite of challenges such as high labour costs, high energy cost, high financing costs, inadequate infrastructure and insufficient government support. In order to be locally and globally competitive, Caribbean manufacturers need to maximize their competitive advantages by exploiting their manufacturing capabilities, despite the challenges they face as a result of their relatively small size. In the first instance, Caribbean manufacturing managers need to ensure that their manufacturing decisions and practices closely match their key competitive priorities. For example, although quality is strongly emphasized the fairly low levels of implementation of quality-related practices suggest that manufacturers are not taking the requisite actions to support a quality strategy. Approximately half of the manufacturers in our study have implemented quality assurance programs while only $18 \%$ have obtained ISO 9000 certification. Caribbean manufacturers therefore need to focus on improving practices in quality management systems such as statistical process control and total quality management (TQM) as ways of achieving consistent quality. In addition, because of the high operational costs Caribbean manufacturers could consider implementing cost-reduction and efficiency systems such as Six Sigma and lean manufacturing to support their emphasis on low-cost manufacturing.

One way in which Caribbean governments and local manufacturing associations are fighting back against the flood of imported goods into the region is by actively promoting 'buy local' campaigns. The objectives of these campaigns are to boost the local manufacturing sectors by encouraging consumers to "buy local, build local' and also to expose consumers to the inter-linkages with the economy and how these can be advanced through their support of local products. We believe this campaign can be further strengthened by twinning these objectives to environmental sustainability, which has now become a new competitive priority. As Caribbean consumers become more environmentally savvy, sustainability could become a competitive differentiator and a major factor in their purchasing decisions. Manufacturing associations can therefore espouse the environmental benefits of buying local such as the potential for lower environmental impact resulting from reduced transportation as well as increased opportunities for product take-back and recycling.

Another strategy recommendation is for Caribbean manufacturers to focus on niche manufacturing. Whereas large economies like China and Brazil can compete based on low prices and large scale production, Caribbean economies may have to select competitive niches that will allow them to sell small volumes at high margins. The OTF Group (2005) believes that most countries in the Caribbean can only profitably compete in the manufacturing sector by developing and exporting to niche markets where consumers are not price sensitive and products are not based on low labour costs. An example of this is pharmaceutical manufacturing in Puerto Rico, which is now the $5^{\text {th }}$ largest area in the world for pharmaceutical manufacturing. Since the domestic market is not very large, governments need to help local manufacturers develop lasting capabilities by providing the requisite support systems for sustained growth of niche manufacturing. Developing such capabilities may be a more effective approach for the sustainability of the regional manufacturing industry.

At present Caribbean manufacturers are not strongly emphasizing capabilities in flexibility and delivery. Greater use of automated and flexible production processes can facilitate this. However, as Khanna and Palepu (2006) note, lack of access to capital makes it difficult for firms in developing countries to invest in technology to achieve flexibility in their operations. Regional governments should therefore be encouraged to provide financial incentives, such as low-interest loans, to manufacturers to invest in automated manufacturing systems.

\subsection{Limitations and future work}

This study provided some insight into the competitive priorities emphasized by Caribbean manufacturers. This preliminary study is significant as there is little empirical research on firm level competitive strategies of manufacturing plants in the Caribbean. However there are some limitations to this study that should be considered when interpreting the findings. First, the small sample size means that the results cannot be 
generalized to all manufacturing sectors throughout the entire Caribbean region. Second, the small number of manufacturing firms in each sector did not allow for cross-sectoral comparisons. A more comprehensive study that focuses on several firms in the same industrial sector could be valuable in formulating sector-specific strategies that can help firms in a specific sector to exploit their manufacturing capabilities for competitive advantage. Third, we note that the data was collected from a single respondent in each company, and as such the possibility of response bias.

Amoako-Gyampah and Boye (2001) point out that an understanding of the business environment is important in the formulation of manufacturing strategy, therefore future research can extend this theory for the Caribbean by examining how the environment within which manufacturing firms operate (such as culture, labour availability and political environment) influences the types of competitive strategies emphasized. Although this study reveals no evidence of trade-offs among competitive priorities, future work could develop and extend the theory on the sand-cone model by Ferdows and De Meyer (1990) by looking at the sequence of capability development in Caribbean firms. Finally, a comprehensive study that examines the relationships between the competitive priorities emphasized and business performance will certainly be useful to manufacturers in the region.

\section{References}

[1]. Amoako-Gyampah, K. (2003). The relationships among selected business environment factors and manufacturing strategy: insights from an emerging economy. Omega, 31(4), 287-301.

[2]. Amoako-Gyampah, K. \& Acquaah, M. (2008). Manufacturing strategy, competitive strategy and firm performance. International Journal of Production Economics, 111(2), 575-592.

[3]. Amoako-Gyampah, K. \& Boye, S.S. (2001). Operations strategy in an emerging economy: the case of the Ghanaian manufacturing industry. Journal of Operations Management, 19(1), 59-79.

[4]. Amoako-Gyampah, K. \& Meredith, J.R. (2007). Examining cumulative capabilities in a developing economy. International Journal of Operations and Production Management, 27(9), 928-950.

[5]. Arthur, O. (2004). Caribbean Single Market and Economy: the way forward. Government of Barbados, Barbados.

[6]. Bernal, R. (2000). Globalisation and small developing countries: the imperatives for repositioning”, in Benn, D. \& Hall, K. (Eds.). Globalisation: A calculus of inequality perspectives from the South. Kingston: Ian Randall Publishers, 88-127.

[7]. Boyer, K. \& Lewis, M.W. (2002). Investigating the need for trade-offs in operations strategy. Production and Operations Management, 11(1), 9-20.

[8]. Bülbül, H. (2011). A taxonomy of manufacturing strategies: a study of Turkish automotive industry. African Journal of Business Management, 5(6), 2322-2335.

[9]. Burgess, T.F., Gules, H.K., Gupta, J.N.D., \& Tekin, M. (1998). Competitive priorities, process innovations and time-based competition in the manufacturing sectors of industrializing economies: the case of Turkey. Benchmarking for Quality Management and Technology, 5(4), 304-316.

[10]. CEC (Commission of European Communities) (1996). Commission recommendation of 3 April 1996 concerning the definition of small and medium-sized enterprises. Official Journal L 107, 30/04/1996: 0004-0009 (Document 396X0280).

[11]. Chida, A. (2000). Small enterprise development in the Caribbean. Caribbean Office, Port-of-Spain: International Labour Organisation (ILO).

[12]. Dangayach, G.S. \& Deshmukh, S.G. (2001). Manufacturing strategy, literature review and some issues. International Journal of Operations and Production Management, 21(7), 884-932.

[13]. Dangayach, G.S. \& Deshmukh, S.G. (2003). Evidence of manufacturing strategies in Indian industry: a survey. International Journal of Production Economics, 83(3), 279-298.

[14]. Davis, M.M., Aquilano, N.J., Chase, R.B \& Balakrishan, J. (2005). Fundamentals of Operations Management: $1^{\text {st }}$ Canadian edition. Canada: McGraw-Hill.

[15]. Dilworth, J.B. (1993). Production and Operations Management: Manufacturing and Services, $5^{\text {th }}$ ed. London: McGraw-Hill.

[16]. Downes, A.S. (2004). Arthur Lewis and Industrial Development in the Caribbean. Paper presented at The Lewis Model after 50 years: Assessing Sir Arthur Lewis' Contribution to Development Economics and Policy, 6-7 July, University of Manchester.

[17]. ECLAC (1999). Competitiveness of the manufacturing and agro-industrial sectors in the Caribbean with a focus on Dominica, Guyana, Saint Vincent and the Grenadines and Trinidad and Tobago. 15 November, LC/CAR/G.576.

[18]. ECLAC, 2002. Globalization and development. 15 April, LC/G.2157 (SES.29/3).

[19]. ECLAC (2007). Trade liberalization, trade performance and competitiveness in the Caribbean. 6 September, LC/CAR/L.136.

[20]. Ferdows, K. \& De Meyer, A. (1990). Lasting improvements in manufacturing performance: in search of a new theory. Journal of Operations Management, 9(2), 168-184.

[21]. Flynn, B.B. \& Flynn, E.J. (2004). An exploratory study of the nature of cumulative capabilities. Journal of Operations Management, 22(5), 439-457.

[22]. Garvin, D.A. (1987). Competing on the 8 dimensions of quality. Harvard Business Review, November-December,101-109.

[23]. Hayes, R.H. \& Wheelwright, S.C. (1984). Restoring our competitive edge: competing through manufacturing. New York: Wiley.

[24]. Kathuria, R. (2000). Competitive priorities and managerial performance: a taxonomy of small manufacturers. Journal of Operations Management, 18(6), 627-641.

[25]. Khanna, T. \& Palepu, K.G. (2006). Emerging giants; building world-class companies in developing countries. Harvard Business Review, 84, 60-69.

[26]. Koufteros, X.A., Vonderembse, M.A. \& Doll, W.J. (2002). Examining the competitive capabilities of manufacturing firms. Structural Equation Modeling, 9(2), 256-282.

[27]. Krüger, L.P. (1997). Strategic manufacturing priorities for South African manufacturers: the need to shift emphasis and improve on current performance. South African Journal of Business Management, 28(4), 138-146.

[28]. Krüger, L.P. (2012). Developing operations strategies - reassessing the strengths and importance of competitive operations priorities for South African businesses. South African Journal of Business Management, 43(3), 13-28.

[29]. Lawrence, W.W. (2007). Small business operations strategy: aligning priorities and resources. Journal of Small Business Strategy, $18(2), 89-103$. 
[30]. Leong, G.K., Snyder, D.L. \& Ward, P.T. (1990). Research in the process and content of manufacturing strategy. Omega, 18(2), $109-122$.

[31]. MTI (Ministry of Trade and Industry), (2011). Key Caribbean sectors. 3rd China-Caribbean Economic Trade Cooperation Forum, 12-13 Sep, Hyatt Regency, Trinidad.

[32]. Nakane, J. (1986). Manufacturing futures survey in Japan: a comparative survey, 1983-1986. System Science Institute, Waseda University, Tokyo.

[33]. Naqshbandi, M.M. \& Idris, F. (2012). Competitive priorities in Malaysian service industry. Business Strategy Series, 13(6), 263273.

[34]. Noble, M.A. (1995). Manufacturing strategy: testing the cumulative model in a multiple country context. Decision Sciences, 25(5), 693-721.

[35]. Nunnally, J. (1978). Psychometric theory. New York: McGraw-Hill.

[36]. OTF Group (2005). Improving competitiveness and increasing economic diversification in the Caribbean: The role of Information and Communication Technologies. Washington DC: infoDev / World Bank.

[37]. Phusavat, K. \& Kanchana, R. (2007). Competitive priorities of manufacturing firms in Thailand. Industrial Management and Data Systems, 107(7), 979-996.

[38]. Phusavat, K. \& Kanchana, R. (2008). Competitive priorities for service providers: perspectives from Thailand. Industrial Management and Data Systems, 108(1), 5-21.

[39]. Robb, D. \& Xie, B. (2003). A survey of manufacturing strategy and technology in the Chinese furniture industry. European Management Journal, 21(4), 484-96.

[40]. Rosenzweig, E.D. \& Roth, A.V. (2004). Towards a theory of competitive progression: evidence from high-tech manufacturing. Production and Operations Management, 13(4), 354-368.

[41]. Rosli, M.M. (2012). Competitive strategy of Malaysian small and medium enterprises: an exploratory investigation. American International Journal of Contemporary Research, 2(1), 93-105.

[42]. Sakhter, S., \& Pounder, P. (2008). Economic globalization and Caribbean economies: competitive developments, strategic response and performance. The Global Studies Journal, 1(4), 69-77.

[43]. Schoenherr, T., Power, D., Narasimhan, R. \& Samson, D. (2012). Competitive capabilities among manufacturing plants in developing, emerging and industrialized countries: a comparative analysis. Decision Sciences, 43(1), 37-71.

[44]. Skinner, W. (1969). Manufacturing - missing link in corporate strategy. Harvard Business Review, May-June, $136-145$.

[45]. Skinner, W. (1974). The focused factory. Harvard Business Review, May-June, 113-121.

[46]. Spring, M. \& Boaden, R. (1997). One more time, how do you win orders: a critical reappraisal of the Hill's manufacturing strategy framework. International Journal of Operations and Production Management, 20(4), 441-67.

[47]. Sum, C-C., Kow, L. S-J. \& Chen, C-S. (2004). A taxonomy of operations strategies of high performing small and medium enterprises in Singapore. International Journal of Operations and Production Management, 24(3/4), 321-345.

[48]. Takala, J., Hirvela, J., Galczynska, A., Lehtonen, M., Rinta-Rahko, S., \& Virta, K. (2003). Competitive priorities of manufacturing strategies: case study at Wartsila. Department of Industrial Management, University of Vaasa, Finland.

[49]. Thürer, M., Filho, M.G., Stevenson, M., \& Fredendall, L.D. (2013). Competitive priorities of small manufacturers in Brazil. Industrial Management \& Data Systems, 113(6), 856-874.

[50]. Vickery, S.K., Droge, C., \& Markland, R.E. (1997). Dimensions of manufacturing strength in the furniture industry. Journal of Operations Management, 15(4), 317-330.

[51]. Ward, P.T., McCreery, J.K., Ritzman, L.P. \& Sharma, D. (1998). Competitive priorities in operations management. Decision Sciences, 29(4), 1035-1046.

[52]. Ward, P. \& Duray, R. (2000). Manufacturing strategy in context: environment, competitive strategy and manufacturing strategy. Journal of Operations Management, 18(2), 123-138.

[53]. White, G.P. (1996). A meta-analysis model of manufacturing capabilities. Journal of Operations Management, 14(4), 315-331.

[54]. Zhao, X., Yeung, J.H.Y. \& Zhou, Q. (2002). Competitive priorities of enterprises in mainland China. Total Quality Management, 13(3), 285-300. 